\title{
Platelet-rich plasma in hamstring muscle injuries in professional soccer players. A pilot study
}

\author{
E. Bezuglovi,2, N. Maffulli3,4,5, A. Tokareva ${ }^{6}$, E. Achkasov ${ }^{1}$
}

1 Department of Sport Medicine, Sechenov First Moscow State Medical University (Sechenov University), Moscow, Russian Federation

2 Russian National Soccer Team, Moscow, Russian Federation

3 Department of Musculoskeletal Disorders, University of Salerno School of Medicine, Surgery and Dentistry, Salerno, Italy

${ }^{4}$ Centre for Sports and Exercise Medicine, Queen Mary University of London, London, UK

5 Institute of Science and Technology in Medicine, Keele University School of Medicine, Stoke on Trent, UK

${ }^{6}$ Department of Orthopaedics No1, Pirogov National Medical \& Surgical Center, Moscow, Russian Federation

\section{CORRESPONDING AUTHOR:}

\section{Nicola Maffulli}

Department of Musculoskeletal Disorders

Faculty of Medicine, Surgery and Dentistry

University of Salerno

Via Allende

Baronissi (Salerno), ITALY

email: n.maffulli@qmul.ac.uk

DOI:

10.32098/mltj.01.2019.20

\begin{abstract}
SUMMARY
Background. This study evaluated the efficacy of a single injection of Platelet-rich plasma (PRP) in the management of hamstring injuries (grade $2 \mathrm{a}$ and $2 \mathrm{~b}$ according to the British Athletics Muscle Injury Classification) in professional soccer players. Methods. Forty professional male soccer players with an acute hamstring injury, verified by MRI, were randomly treated either conservatively (physiotherapy, exercises) or with a combination of conservative methods and injections of PRP. Results. The time to return to sport (RTS) in the PRP group (11.4 \pm 1.2 days) was significantly shorter than in the other group $(21.3 \pm 2.7$ days; $\mathrm{p}<0.05)$. There were no episodes of reinjury in both groups at a minimum of 6 months of follow-up. Conclusions. The use of PRP exerts a beneficial effect on pain relief and allows earlier return to sport.
\end{abstract}

\section{KEY WORDS}

acute muscle injury; football players; bamstrings bealing; muscle injury classification; pain scale

\section{INTRODUCTION}

Muscle injuries are very prevalent in soccer players. During a competition season, a team of elite soccer players of 25 can expect 4-6 injuries of the hamstring muscle group (1). The biceps femoris is the most frequently injured muscle $(83 \%)$, followed by the semimembranosus and semitendinosus, $12 \%$ and $5 \%$ respectively (2). Most hamstring muscle injuries are minor, but they influence the quality of play. In addition, the time off needed to return to sport is around 14 days, with an average of 3-4 games missed (3). The rate of re-injury in these athletes is $16-18 \%$ (4-5). To successfully manage these muscle lesions, it is necessary to effect an accurate diagnosis, evaluate correctly the pain, and plan an appropriate rehabilitation programme. The diagnosis is based on clinical assessment complemented by imaging (MRI or ultrasound scanning [US]).

Classification of muscle injuries plays an important role, and should help health care professional to plan adequate management (6). Several classifications of muscle injuries are available, according to the stage and location of damage and the functional impairment caused (4-5). For example, the classification proposed by Chan et al. (7) covers location of the injury, functional disorder and spread of rupture. A prognostic indicator is the time taken to walk pain-free (8). Recently, injection of platelet-rich plasma (PRP) to injured musculoskeletal soft tissue has become widespread, with contrasting results (9-10), ranging from no benefit of a single injection of PRP in hamstring muscle injuries (11) to better biological healing, but no difference in the time of healing (12). Some data show favourable results of PRP in musculoskeletal soft tissue injuries, shortening the time to recovery (13).

The present study reports the result of a pilot study on the combined use of PRP and physiotherapy versus physiotherapy alone in the management of hamstring injuring in professional soccer players. 


\section{MATERIALS AND METHODS}

\section{Study design}

Forty male professional football players (mean $27 \pm 3.3$ years, range 22 to $31, p<0.05$ ) were enrolled from clubs of Russian Football Premier League and Russian Football National League over 26 months (from December 2014 to January 2017). All subjects sustained an acute primary isolated hamstring injury. Each athlete underwent full clinical examination, focusing on the mechanism of injury and pain location. $70 \%$ of the hamstring injuries occurred while sprinting during a match or a training session, and the remaining $30 \%$ in forced high elevation of the leg or stretching to reach a ball. All athletes stopped playing immediately after the injury. The diagnosis was verified by high-resolution real-time ultrasonography (US) (iU-22 X-MATRIX, Philips, USA) as a first-line imaging modality, and verified by MRI 24 - 48 hours after the injury event (14) using 1.5 Tesla MRI (Siemens Magnetom AERA 1.5T) scanning. The type of treatment depends on the stage of injury, a reason why diagnosis has to be accurate. The British Athletics Muscle Injury Classification was used for this study. Only subjects with $2 \mathrm{a}$ and $2 \mathrm{~b}$ hamstring lesions were eligible for the study. According to the British Athletics muscle injury classification, a 2 a lesion is an injury that extend from the peripheral fascia into the muscle; $a 2 b$ lesion is located within the muscle or at the muscle tendon junction. On MRI of both $2 \mathrm{a}$ and $2 \mathrm{~b}$ lesion, the high signal change will either measure between $10 \%$ and $50 \%$ of the cross-sectional area of that individual muscle at the site of injury or extend between 5 and $15 \mathrm{~cm}$ within the muscle; there is architectural fibre disruption less than $5 \mathrm{~cm}$ (15). Before the treatment, all athletes applied cold 3 times per day for 30 minutes.

\section{Randomization}

Randomization was performed after subjects were deemed eligible and had provided informed consent (see table I).

Table I - CONSORT 2010 checklist.

\section{CONSORT 2010 checklist of information to include when reporting a randomised trial*}

\begin{tabular}{|c|c|c|c|}
\hline Section/Topic & $\begin{array}{l}\text { Item } \\
\text { No }\end{array}$ & Checklist item & $\begin{array}{l}\text { Reported } \\
\text { on page No }\end{array}$ \\
\hline \multicolumn{4}{|l|}{ Title and abstract } \\
\hline & $1 \mathrm{a}$ & Identification as a randomised trial in the title & 1 \\
\hline & $1 b$ & Structured summary of trial design, methods, results, and conclusions (for specific guidance see CONSORT for abstracts) & 2 \\
\hline \multicolumn{4}{|l|}{ Introduction } \\
\hline Background and & $2 a$ & Scientific background and explanation of rationale & 3 \\
\hline objectives & $2 b$ & Specific objectives or hypotheses & 3 \\
\hline \multicolumn{4}{|l|}{ Methods } \\
\hline \multirow[t]{2}{*}{ Trial design } & 3a & Description of trial design (such as parallel, factorial) including allocation ratio & 4 \\
\hline & $3 b$ & Important changes to methods after trial commencement (such as eligibility criteria), with reasons & 4 \\
\hline \multirow[t]{2}{*}{ Participants } & $4 \mathrm{a}$ & Eligibility criteria for participants & 4 \\
\hline & $4 b$ & Settings and locations where the data were collected & 4 \\
\hline Interventions & 5 & $\begin{array}{l}\text { The interventions for each group with sufficient details to allow replication, including how and when they were } \\
\text { actually administered }\end{array}$ & 4 \\
\hline \multirow[t]{2}{*}{ Outcomes } & $6 a$ & $\begin{array}{l}\text { Completely defined pre-specified primary and secondary outcome measures, including how and when they } \\
\text { were assessed }\end{array}$ & 4 \\
\hline & $6 b$ & Any changes to trial outcomes after the trial commenced, with reasons & 4 \\
\hline \multirow[t]{2}{*}{ Sample size } & $7 a$ & How sample size was determined & - \\
\hline & $7 \mathrm{~b}$ & When applicable, explanation of any interim analyses and stopping guidelines & - \\
\hline \multicolumn{4}{|l|}{ Randomisation: } \\
\hline \multirow{2}{*}{$\begin{array}{l}\text { Sequence } \\
\text { generation }\end{array}$} & $8 \mathrm{a}$ & Method used to generate the random allocation sequence & 5 \\
\hline & $8 b$ & Type of randomisation; details of any restriction (such as blocking and block size) & 5 \\
\hline $\begin{array}{l}\text { Allocation } \\
\text { concealment } \\
\text { mechanism }\end{array}$ & 9 & $\begin{array}{l}\text { Mechanism used to implement the random allocation sequence (such as sequentially numbered containers), } \\
\text { describing any steps taken to conceal the sequence until interventions were assigned }\end{array}$ & 5 \\
\hline Implementation & 10 & $\begin{array}{l}\text { Who generated the random allocation sequence, who enrolled participants, and who assigned participants to } \\
\text { interventions }\end{array}$ & 5 \\
\hline Blinding & $11 a$ & If done, who was blinded after assignment to interventions (for example, participants, care providers, those & 6 \\
\hline
\end{tabular}


A computer was used to produce a randomization schedule. The trial manager provided treatment assignments placed in sequentially numbered opaque envelopes. Patients were randomized on a 1:1 basis (see figure 1).

Group 1 (20 patients) subjects were rehabilitated using traditional methods: physiotherapy (cold therapy 30 minutes 3 times per day first 3 days, magnetotherapy for 30 minutes once a day for 7 days, myostimulation in "analgesic" and "active recovery" program) and increasing physical activity. Group 2 (20 patients) subjects were treated conservatively in the same fashion as Group 1 subjects, and also received an injection of PRP. No non-steroidal anti-inflammatory drugs were used. Of the 20 athletes in Group 1, 12 suffered a biceps femoris injury at the muscle-tendon junction, 4 an injury to the semimembranosus, and 4 an injury to the semitendinosus muscle. Of the 20 athletes in Group 2, 14 suffered a biceps femoris injury at the muscle-tendon junction, and 6 a semimembranosus muscle injury.

There were 20 patients with $2 \mathrm{a}$ and 20 patients with $2 \mathrm{~b}$ stages of injury in both groups (see Table II).

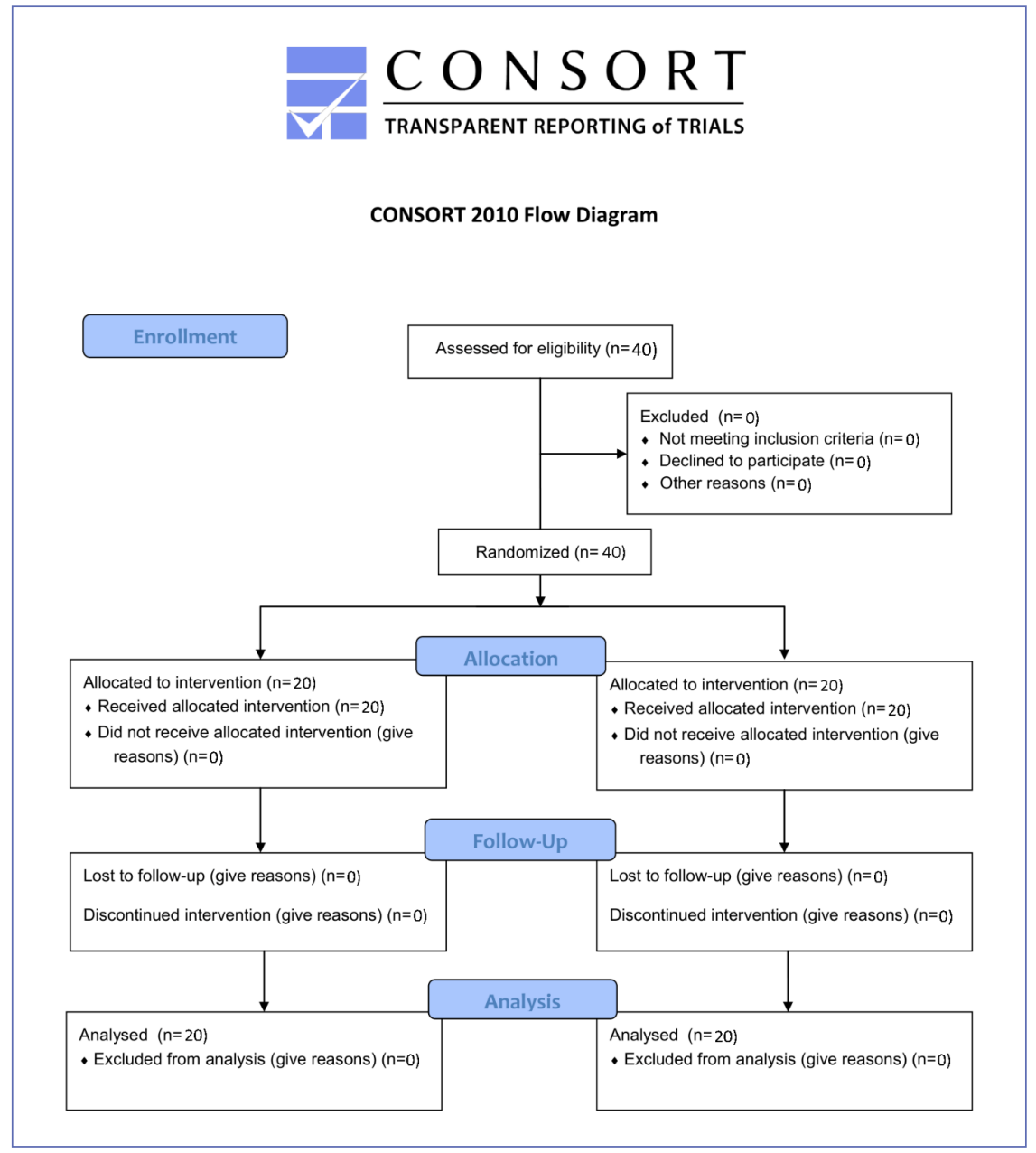

Figure 1 - CONSORT Flow Diagram.

Table II - Distribution by grade in each muscle in 2 groups (number of patients).

\begin{tabular}{|c|c|c|c|c|c|c|}
\hline Grade & $\begin{array}{c}\text { m. biceps } \\
\text { femoris } 2 a \\
\text { stage of injury }\end{array}$ & $\begin{array}{c}\text { m. biceps } \\
\text { femoris } 2 b \\
\text { stage of injury }\end{array}$ & $\begin{array}{l}\text { m. semimembranosus } \\
\text { 2a stage of injury }\end{array}$ & $\begin{array}{c}\mathrm{m} . \\
\text { semimembranosus } \\
\text { 2b stage of injury }\end{array}$ & $\begin{array}{c}\mathrm{m} . \\
\text { semitendinosus } \\
\text { 2a stage of injury }\end{array}$ & $\begin{array}{c}\text { m. } \\
\text { semitendinosus } \\
\text { 2b stage of injury }\end{array}$ \\
\hline Group 1 & 4 & 8 & 3 & 1 & 3 & 1 \\
\hline Group 2 & 6 & 8 & 4 & 2 & & \\
\hline
\end{tabular}




\section{Intervention}

We withdrew $56 \mathrm{~mL}$ of venous blood from the cubital vein with a butterfly needle into eight $9 \mathrm{~mL}$ tubes, each containing sodium citrate $0.4 \mathrm{~mL}$ (TE9, Vacuette) (16).

For Group 2, the Plasma Rich in Growth Factors (PRGF) was prepared using the Endoret PRGF System BTI 4 centrifuge (BTI Biotechnology Institute UK Ltd, Colchester, England), using a standard protocol, $1800 \mathrm{rpm}$ for 8 minutes. The tubes were centrifuged immediately after blood extraction following the manufacturer's protocol.

A laboratory pipette was used to withdraw $1 \mathrm{~mL}$ of the fraction with the highest platelet concentration (middle layer, fraction 3) in each tube without touching the buffy coat, located above the erythrocyte layer, that consist mostly of leucocytes.

At least 700,000 platelets in $1 \mathrm{~mL}$ of fluid were injected in the injury site after activation with $\mathrm{CaCl}_{2}(20 \mu \mathrm{L}$ per milliliter of plasma).

\section{Injection procedure and blinding}

Patients were prone on a surgical table during the procedure. The posterior thigh was cleaned with Betadine. As part of the blinding technique, a blood sample was obtained from all patients. Preparation of the two injectants took place out of sight of the athlete. All the patients were blindfolded during blood sampling and while receiving the intervention. Group 2 subjects received a single injection of $8 \mathrm{~mL}$ of platelet-rich plasma injected to the injured part of muscle under US control.

Group 1 subjects received a single injection of $8 \mathrm{~mL}$ of $0.9 \%$ $\mathrm{NaCl}$ injected to the injured part of muscle under US control.

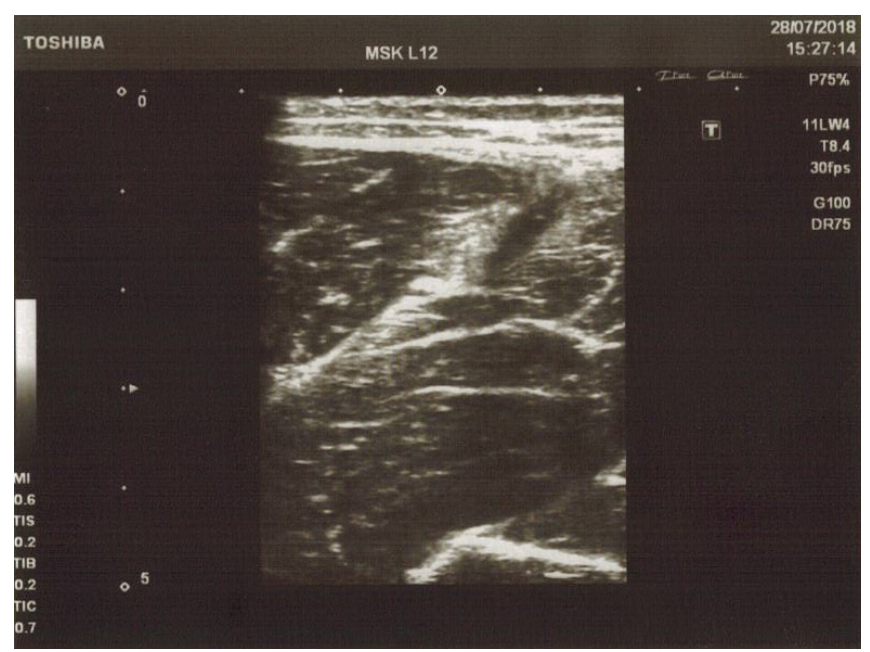

Figure 2 - Needle penetrating the injured area.
After the injection, a sterile dressing was placed over the site of injection. Ice was applied for approximately 15 minutes. The athletes abstained from training for 2 days, during which they applied cold compresses to the area injected.

Pain was evaluated using a 10 points scale (table III). Both groups had similar results (Group 1, $7.8 \pm 0.5$ points; Group $2,7.6 \pm 0.3$ ).

The patients and outcome assessors were blinded to the treatment, but the treating physician and trial manager were not.

\section{Data analysis}

Per each athlete, we recorded the number of days from the injury to the beginning of full trainings, and any re-injury

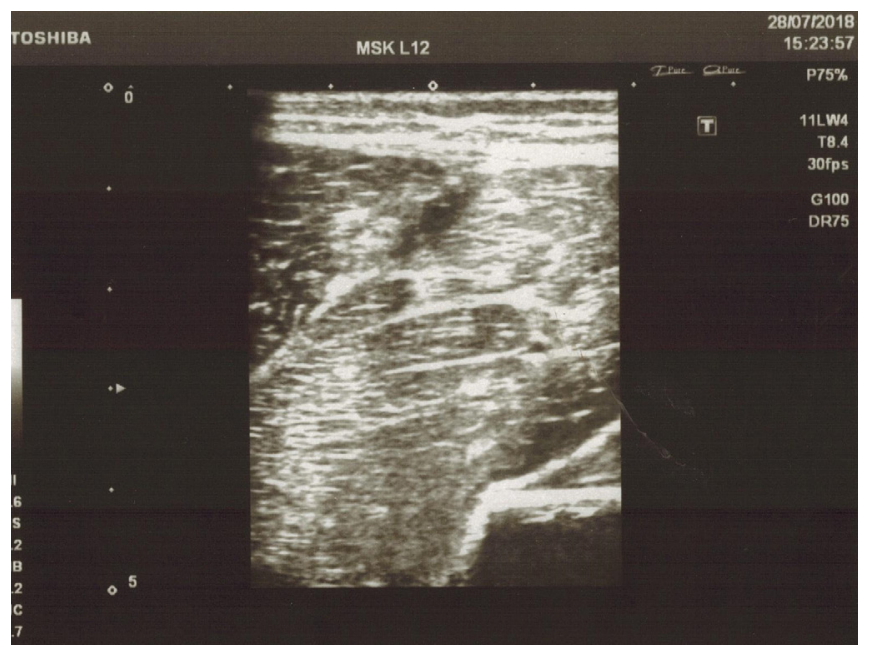

Figure 3 - Area of injury.

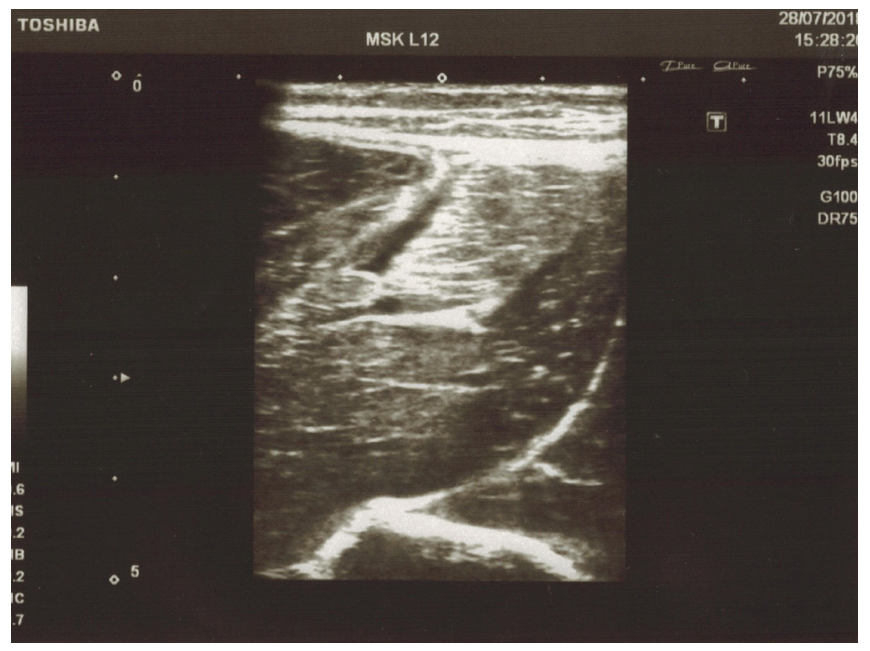

Figure 4 - Area filled with PRP after the end of the injection. 
Table III - Pain assessment scale for professional soccer players.

\begin{tabular}{cl}
\hline Score & Characteristics of pain intensity and condition of its appearance \\
\hline $\mathbf{1}$ & performing exercises of any intensity, no pain (after the exercises there is no sense of heaviness in a muscle). \\
\hline $\mathbf{2}$ & performing exercises of any intensity, no pain (after the exercises there is a sense of heaviness in a muscle). \\
\hline $\mathbf{4}$ & $\begin{array}{l}\text { performing exercises of any intensity, no pain (there is sense of heaviness in muscle in the second part } \\
\text { of exercise program). }\end{array}$ \\
\hline $\mathbf{5}$ & $\begin{array}{l}\text { soccer specific exercises (jumping on a unstable platform }(40 \mathrm{~cm}), \text { jumping down and sprint for } 10 \mathrm{~meters}), \text { no pain. } \\
\text { direction every } 10 \text { meters), no pain. }\end{array}$ \\
\hline $\mathbf{6}$ & running at medium intensity (speed $12 \mathrm{~km} / \mathrm{h})$, no pain. \\
\hline $\mathbf{7}$ & deep palpation, no pain. \\
\hline $\mathbf{8}$ & fast walking (speed $7 \mathrm{~km} / \mathrm{h})$, no pain. \\
\hline $\mathbf{1 0}$ & slow walking (speed $5 \mathrm{~km} / \mathrm{h})$, no pain. \\
\hline
\end{tabular}

for a minimum of 6 months of follow-up. The criterion to return to full training, including soccer specific exercises at a high intensity, was pain at a level of 2 or less. Statistical analysis was performed with SPSS 19.0 statistical software (SPSS, Inc., Chicago, IL, USA). Continuous variables were presented as mean standard deviations and analyzed using the Student $t$ test, while categorical data were represented by a both a number and a percentage and were analyzed with the square test. A P value $<0.05$ was as significant. The pain was assessed daily until return to sport. No adverse events were recorded.

All the procedures described in the present investigation were approved by the Ministry of Health of the Russian Federation. The study meets the ethical standards of the journal (16).

\section{RESULTS}

All the soccer players returned to their regular training after treatment. No complications were observed in either group.

The athletes in Group 2, who received a PRP injection, experienced a mean time to return to sport of $11.4 \pm 1.2$ days, significantly shorter than Group 1 athletes $(21.3 \pm 2.7$ days), $\mathrm{p}<0.05$. The average pain level at the time of return to sport in Group 2 was $1.2 \pm 0.2$, and $1.8 \pm 0.4$ in Group 1 (p $<0.05$ ). On the third day after the beginning of treatment, in Group 2 athletes pain had decreased to $4.3 \pm 0.3$, while in Group 2 pain was $6.6 \pm 0.2(\mathrm{p}<0.05)$.

At minimum follow up of 6 months, no re-injuries were observed in both groups.

\section{DISCUSSION}

There is still a paucity of clinical evidence for current prevention and rehabilitation programmes for hamstring injury (17). The present investigation studied the efficacy of a single injection of PRP in the management of hamstring muscle injuries in elite footballers.

All injuries were assessed by MRI 24-48 hours after the index muscle injury, when such examination is considered optimal, and can have prognostic implications $(5,18)$. MRI grades of hamstring muscle injuries are highly associated with the time of absence from football (19-20).

Several researchers (21-22) have indicated that MRI may qualitatively prognosticate lay-off time after hamstring injury. For instance, Rettig et al. (23) reported the association between MRI findings and time to return to play after hamstring injuries in National Football League players. A rapid return to play (1 week or less) is possible if the injury involved isolated contracture of the long head of biceps femoris (LHB), less than $50 \%$ of the cross section, and minimal perimuscular edema (23).

A recent meta-analysis (24) showed that PRP injections may significantly reduce the time to return to sport among patients who have sustained a grade I or II muscle strain without increasing the risk of reinjury at 6 months of follow-up. However, subsequent subgroup analysis did not evidence this difference among patients with a hamstring strain (25-28).

In professional soccer, a return to play approximately 1 week earlier than the average would likely allow an athlete to participate in at least 1 to 2 additional games, thus representing a significant clinical impact (29). 
In the present study, we enrolled only athletes with $2 \mathrm{a}$ and $2 \mathrm{~b}$ hamstring injuries. Guillodo et al. (30) showed that most patients with minor injuries had RTS shorter than 25 days. In contrast, severe hamstring injuries (grade III) may require up to 60 days to heal fully (30).

The time to RTS reported in the present study is comparable to what seen in previous studies involving professional athletes (21-22,31). As such, the data produced by the present investigation are to be considered preliminary, and can be used to inform larger randomized controlled trials.

\section{Limitations}

The present investigation has several limitations. For example, we were not able to perform MRI at follow up. This however would mimic a real-life situation, where clinical

\section{REFERENCES}

1. Waldén M, Hägglund M, Ekstrand J. Time-trends and circumstances surrounding ankle injuries in men's professional football: an 11-year follow-up of the UEFA Champions League injury study. Br J Sports Med 2013; 47(12):748-753.

2. Guermazi A, Roemer FW, Robinson P, Tol JL, Regatte RR, Crema MD. Imaging of muscle injuries in sports medicine: sports imaging series. Radiology 2017; 282(3):646-663.

3. Werner S, Grose R. Regulation of wound healing by growth factors and cytokines. Physiol Rev 2003; 83(3):835-870.

4. Elliott MC, Zarins B, Powell JW, Kenyon CD. Hamstring muscle strains in professional football players: a 10-year review. Am J Sports Med 2011; 39(4):843-850.

5. Hallén A, Ekstrand J. Return to play following muscle injuries in professional footballers. J Sports Sci 2014; 32(13):1229-1236.

6. Maffulli N, Oliva F, Frizziero A, et al. ISMuLT Guidelines for muscle injuries. MLTJ 2013; 3(4):241.

7. Chan O, Del Buono A, Best TM, Maffulli N. Acute muscle strain injuries: a proposed new classification system. Knee Surg Sports Traumatol Arthrosc 2012; 20(11):2356-2362.

8. Orchard JW, Seward H, Orchard JJ. Results of 2 decades of injury surveillance and public release of data in the Australian Football League. Am J Sports Med 2013; 41(4):734-741.

9. Anitua E, Andia I, Ardanza B, Nurden P, Nurden AT. Autologous platelets as a source of proteins for healing and tissue regeneration. Thromb Haemost 2004; 91(1):4-15.

10. Sanchez M, Anitua E, Andia I. Application of autologous growth factors on skeletal muscle healing. In 2nd World Congress on Regenerative Medicine. Podium Presentation 2005.

11. Hamilton B, Tol J, Almusa E, et al. Platelet-rich plasma does not enhance return to play in hamstring injuries: a randomised controlled trial. Br J Sports Med 2015; 49(14):943-950.

12. 12. Zanon G, Combi F, Combi A, et al. Platelet-rich plasma in the treatment of acute hamstring injuries in professional football players. Joints 2016; 4(1).

13. Wright-Carpenter T, Klein P, Schäferhoff $P$, et al. Treatment of muscle injuries by local administration of autologous condi- examination reveals whether an athlete has returned to a level of fitness allowing them to return to play. Our sample is small, and this makes broad generalization difficult. An appropriately powered randomized controlled study with long-term follow-up is needed for more complete assessment of the efficacy of PRP as a treatment option in various degrees of hamstring muscle injuries in professional soccer players.

\section{CONCLUSION}

Platelet-rich plasma injections can be used in the treatment of grade $2 \mathrm{a}-2 \mathrm{~b}$ hamstring injuries in professional soccer players, decreasing the time to return to sport, with no adverse effects in the middle term. PRP injections should be associated to an intensive rehabilitation protocol including physiotherapy and sport specific exercises to optimize recovery.

tioned serum: a pilot study on sportsmen with muscle strains. Int J Sports Med 2004; 25(08):588-593.

14. Gielen JL, Robinson P, Van Dyck P, et al. Muscle injuries. In Imaging of orthopedic sports injuries. Springer Berlin Heidelberg 2007.

15. Pollock N, James SL, Lee JC, Chakraverty R. British athletics muscle injury classification: a new grading system. Br J Sports Med 2014; bjsports 2013.

16. Padulo J, Oliva F, Frizziero A, and Maffulli N. Muscles, Ligaments and Tendons Journal-Basic principles and recommendations in clinical and field Science Research: 2016 Update. MLTJ 2016; 6(1):1.

17. 17. Liu H, Garrett WE, Moorman CT, Yu B. Injury rate, mechanism, and risk factors of hamstring strain injuries in sports: A review of the literature. J Sport Health Sci 2012; 1(2):92-101.

18. Ekstrand J, Waldén M, Hägglund M. Hamstring injuries have increased by $4 \%$ annually in men's professional football, since 2001: a 13-year longitudinal analysis of the UEFA Elite Club injury study. Br J Sports Med 2016; 50(12):731-737.

19. Ekstrand J, Healy JC, Waldén M, et al. Hamstring muscle injuries in professional football: the correlation of MRI findings with return to play. Br J Sports Med 2012; 46(2):112-117.

20. McCall A, Carling C, Nedelec M, et al. Risk factors, testing and preventative strategies for non-contact injuries in professional football: current perceptions and practices of 44 teams from various premier leagues. Br J Sports Med 2014; bjsports 2014.

21. Askling C, Karlsson J, Thorstensson A. Hamstring injury occurrence in elite soccer players after preseason strength training with eccentric overload. Scand J Med Sci Sports 2003; 13(4):244-250.

22. Ekstrand J, Askling C, Magnusson H, Mithoefer K. Return to play after thigh muscle injury in elite football players: Implementation and validation of the Munich muscle injury classification. Br J Sports Med 2013; 47(12):769-774.

23. Rettig AC, Meyer S, Bhadra AK. Platelet-rich plasma in addition to rehabilitation for acute hamstring injuries in NFL play- 
ers: clinical effects and time to return to play. Orthop J Sports Med 2013; 1(1):2325967113494354.

24. Sheth U, Dwyer T, Smith I, et al. Does Platelet-Rich Plasma Lead to Earlier Return to Sport When Compared with Conservative Treatment in Acute Muscle Injuries? A Systematic Review and Meta-analysis. Arthroscopy 2018; 34:281-288.

25. Andia I, Maffulli N. Platelet-rich plasma for muscle injury and tendinopathy. Sports Med Arthrosc Rev 2013; 21(4):191-198.

26. Andia I, Maffulli N. Muscle and tendon injuries: the role of biological interventions to promote and assist healing and recovery. Arthroscopy 2015; 31(5):999-1015.

27. Andia I, Sanchez M, Maffulli N. Tendon healing and platelet-rich plasma therapies. Expert Opin Biol Ther 2010; 10(10):1415-1426.
28. Mei-Dan O, Lippi G, Sánchez M, Andia I, Maffulli N. Autologous platelet-rich plasma: a revolution in soft tissue sports injury management? Phys Sportsmed 2010; 38(4):127-135.

29. Foster TE, Puskas BL, Mandelbaum BR, et al. Platelet-rich plasma: from basic science to clinical applications. Am J Sports Med 2009; 37(11):2259-2272.

30. Guillodo Y, Madouas G, Simon T, et al. Platelet-rich plasma $(\mathrm{PRP})$ treatment of sports-related severe acute hamstring injuries. MLTJ 2015; 5(4):284.

31. Mueller-Wohlfahrt HW, Haensel L, Mithoefer K, et al. Terminology and classification of muscle injuries in sport: a consensus statement. Br J Sports Med 2013; 47:342-350. 